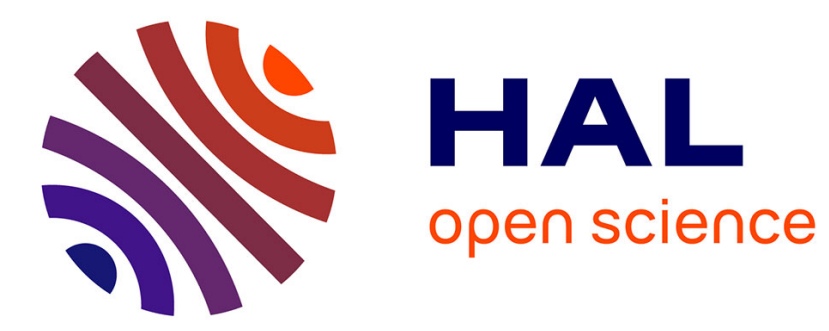

\title{
Laboratory testing and on-site experiments to characterize Corona discharges in VHF-band
}

Guillaume Dehan, Hélène Galiègue, François Issac, Alexandre Chabory

\section{To cite this version:}

Guillaume Dehan, Hélène Galiègue, François Issac, Alexandre Chabory. Laboratory testing and on-site experiments to characterize Corona discharges in VHF-band. URSI GASS 2021, Aug 2021, ROME, Italy. hal-03477970

\author{
HAL Id: hal-03477970 \\ https://hal.science/hal-03477970
}

Submitted on 13 Dec 2021

HAL is a multi-disciplinary open access archive for the deposit and dissemination of scientific research documents, whether they are published or not. The documents may come from teaching and research institutions in France or abroad, or from public or private research centers.
L'archive ouverte pluridisciplinaire HAL, est destinée au dépôt et à la diffusion de documents scientifiques de niveau recherche, publiés ou non, émanant des établissements d'enseignement et de recherche français ou étrangers, des laboratoires publics ou privés. 
URSI GASS 2021, Rome, Italy, 28 August - 4 September 2021

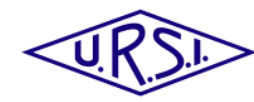

\author{
Laboratory testing and on-site experiments to characterize Corona discharges in VHF-band \\ Guillaume DEHAN $^{(1)(2)}$, Hélène GALIEGUE ${ }^{(2)}$, François ISSAC ${ }^{(1)}$ and Alexandre CHABORY (2) \\ (1) ONERA, 31400 Toulouse, France \\ (2) ENAC, Université de Toulouse, France
}

\begin{abstract}
Corona discharges have been designated as aeronautical VHF communications disturber. In order to better understand the discharges, the coupling phenomena involved and to propose an adequate protection for VHF systems, both laboratory testing and experiments on a $25 \mathrm{~m}$ high pylon are carried out here.
\end{abstract}

Main characteristics of Corona pulses have been retrieved and analyzed wrt the experimental parameters. Leader propagation phenomena have also been identified.

\section{Introduction}

For decades, VHF communications have been disrupted at ground stations. Several sources of noise are known to interfere with VHF communications and most of them have been treated [1] [2] [3] [4]. Although solutions have been found for this problem, interference phenomena still exist, in particular in aeronautical VHF communications. These interferences have been attributed to corona discharges [5] i.e., electrostatic discharges which can occur at the top of pylon, equipped with VHF antennas, during stormy weather. Yet, the sufficient intensity of the disturbance to interfere with a communication system is not known. It is therefore interesting to know if discharges appear in several places and at what intensity they shall cause interferences to communications.

The objective of this paper is to show that these experiments can help to propose a better modeling of the problem as well as a better understanding of the couplings to finally find solutions of protection against these disturbances.

In this article, the first section presents the experimental setup of both laboratory experience and measurements on a test pylon secondly, the results obtained are shown and analyzed.

\section{Experimental setup}

To evaluate the intensity and locations of the phenomenon, experiments are carried out on a 1,5 m high model pylon and on a $25 \mathrm{~m}$ test pylon.

\section{a. Laboratory experiment}

The laboratory experiment consists in building a simulation of our problem with the objective of controlling the electrostatic aggression on a model pylon. This allows us to test VHF links and show disturbances on VHF links and to develop measurement techniques.

For the laboratory experiment, we have a model pylon of $143 \mathrm{~cm}$ high structure made of steel with a triangular base with a lightning rod of $10 \mathrm{~cm}$ length at the top, the whole structure is grounded. A metal plate with negative high voltage is placed $7 \mathrm{~cm}$ above the pylon. We use a bipolar high-voltage power supply up to $70 \mathrm{kV}$. The pylon is shown in Fig. 1.

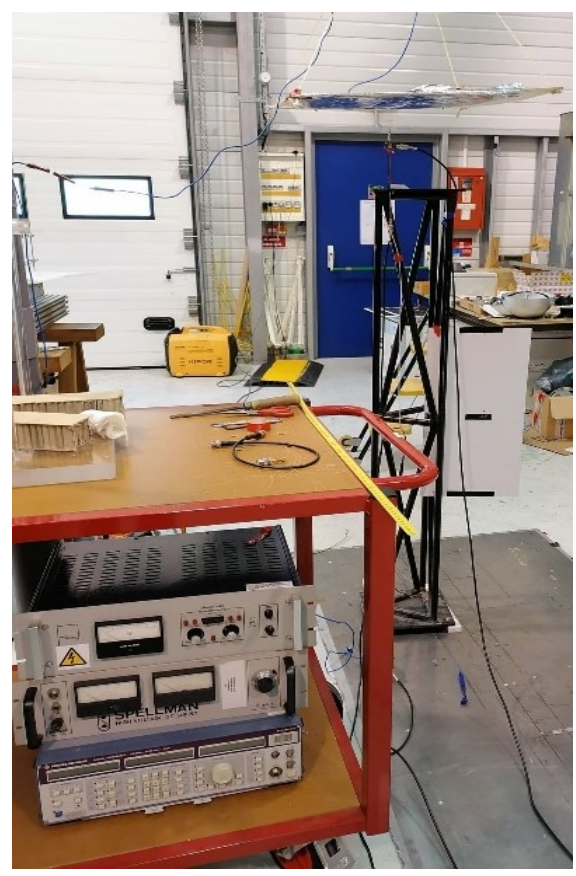

Fig. 1: Model pylon

Current measurements are performed at the lightning rod with a shunt at the top and a probe at the base, to compare these different techniques. For the base of the pylon, there is one current probe to measure all the currents on the metallic structure. The current probes are Pearson transformers of $1 \mathrm{~V} / \mathrm{A}$ and $2 \mathrm{~V} / \mathrm{A}$ ratio. They are placed in order to measure a negative current when negative discharges occur.

b. Pylon test acquisition system

The instrumentation of the test pylon allows us to have a better understanding of the EMC of the pylon. 
The test pylon is a square based pylon of dimensions $25 \mathrm{~m}$ x $0.5 \mathrm{~m}$ x $0.5 \mathrm{~m}$ made of steel and shown in Fig. 2. It has a $1 \mathrm{~m}$ lightning rod at the top and is grounded. We use two currents probes to measure the current at the base of the pylon, around the ground cable, and at the base of the lightning rod. The acquisition system is placed in a local next to the pylon and works autonomously. The trigger is set to $20 \mathrm{~mA}$ and we receive the data via emails as shown in Fig. 3.

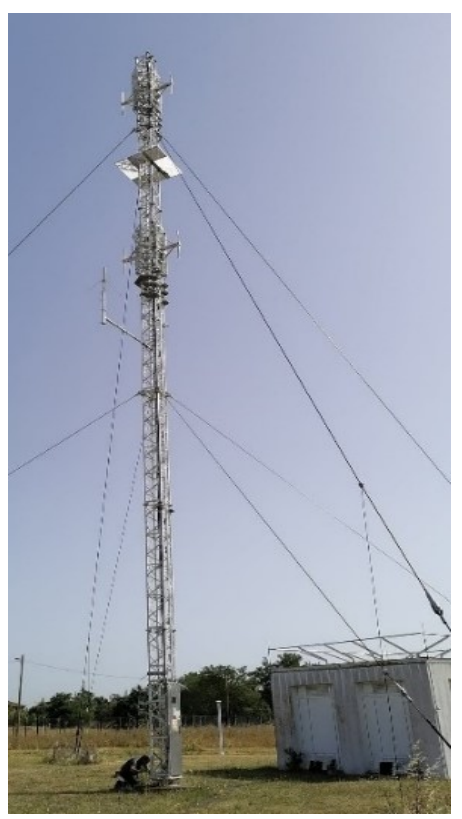

Fig. 2: Test pylon

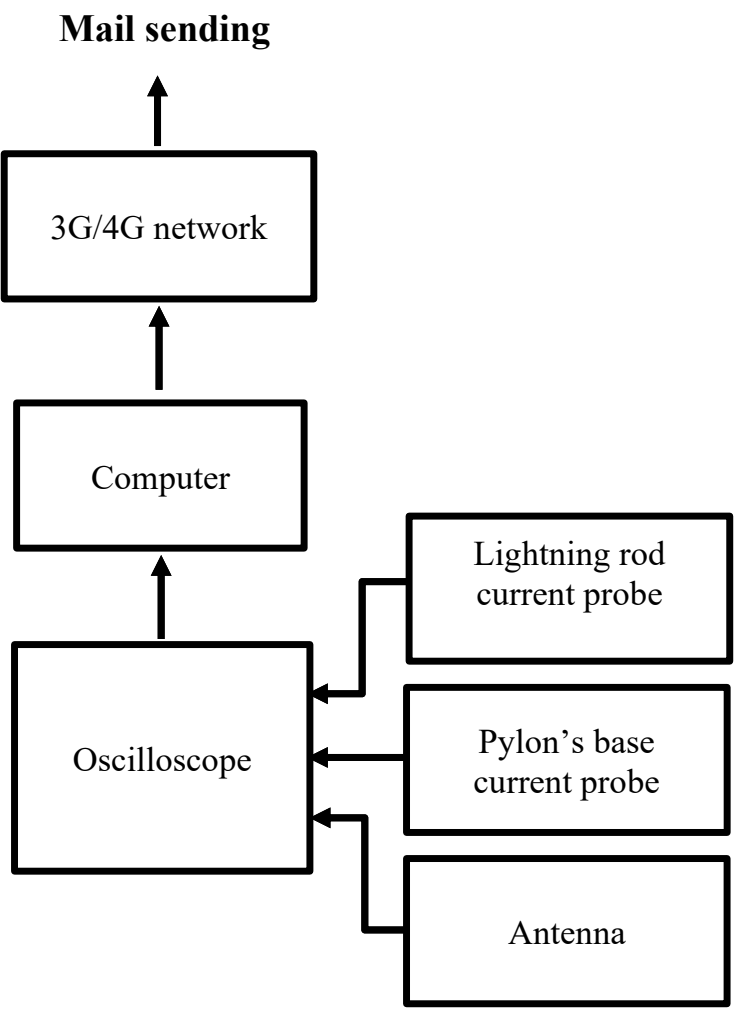

Fig. 3 : Schema of the acquisition system

\section{Results analysis}

In this section we compare currents that we measured on both experiments.

With an oscilloscope, we measure the current at the top of the model pylon and at the base to compare both currents and to check the correlation between both. The oscilloscope averages 100 curves to get rid of the noise and to average the amplitude. The result is shown in Fig. 4.

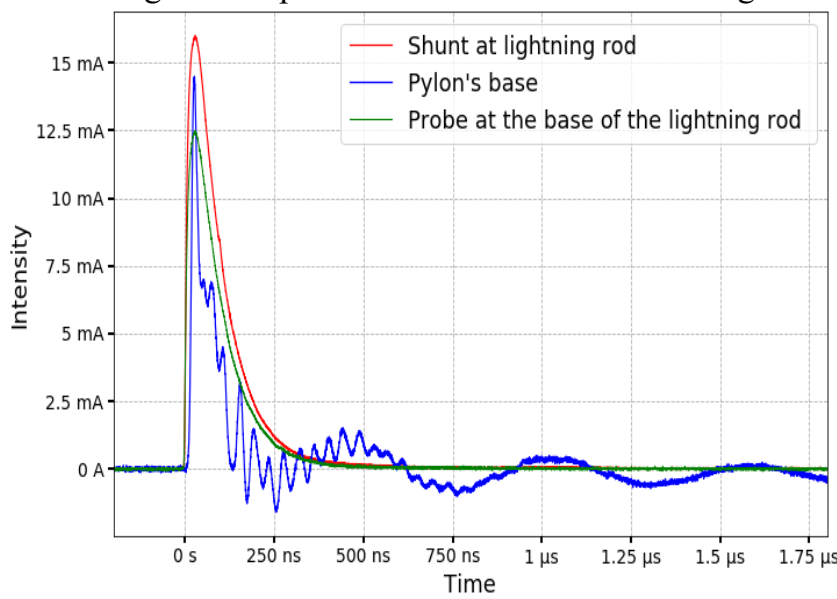

Fig. 4: Current measurements on the model pylon

At the top of the pylon, we observe a pulse of about $15 \mathrm{~mA}$ with a duration of about $200 \mathrm{~ns}$. The amplitude is higher for the shunt than at the base of the lightning rod. The shape of pulses on the Fig. 4 is the same than we normally observe for corona discharge. [5] [6]

The current measured at the base of the pylon correlates perfectly with the discharge current measured at the top. Contrary to the lightning rod measurements, they show resonance related to the geometry of the pylon, that can be modeled as a transfer function. This result is important because it helps to evaluate the density of corona event on a structure without having to measure all the locations where discharge occur.

The current probes on the $25-\mathrm{m}$ high test pylon have measured different types of phenomena. First, when the trigger is set at the lightning rod level, it has triggered more

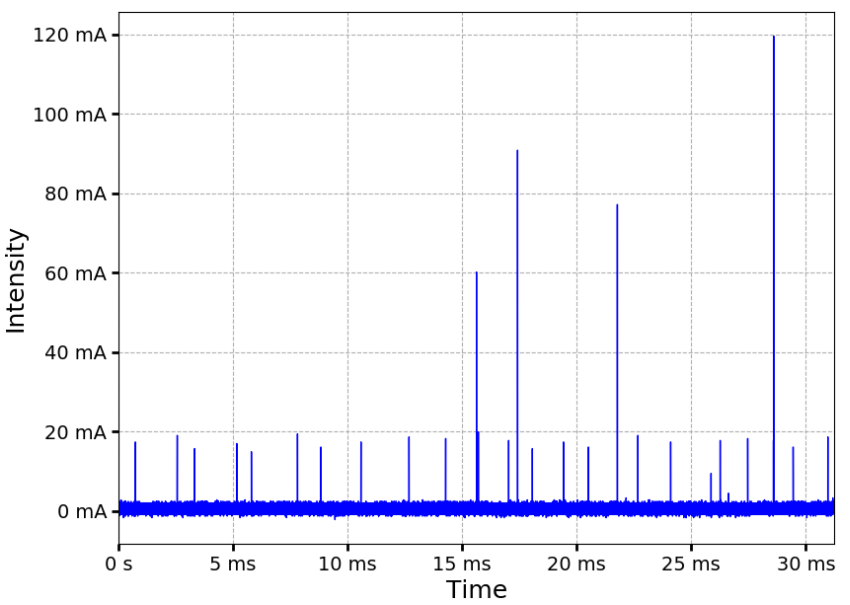

Fig. 5: Current measurement at the lightning rod on the test pylon 
than 60 times in one day. One of the results is shown in Fig. 5 and illustrates a strong corona activity with pulses of intensity up to $120 \mathrm{~mA}$. The pulse shown in Fig. 6 has an amplitude of $75 \mathrm{~mA}$ and lasts almost $1 \mu \mathrm{s}$. It is similar in shape to the one observed on the laboratory pylon. The intensity and frequency of the impulses vary from one result to another, but the impulses all follow bi-exponential type laws.

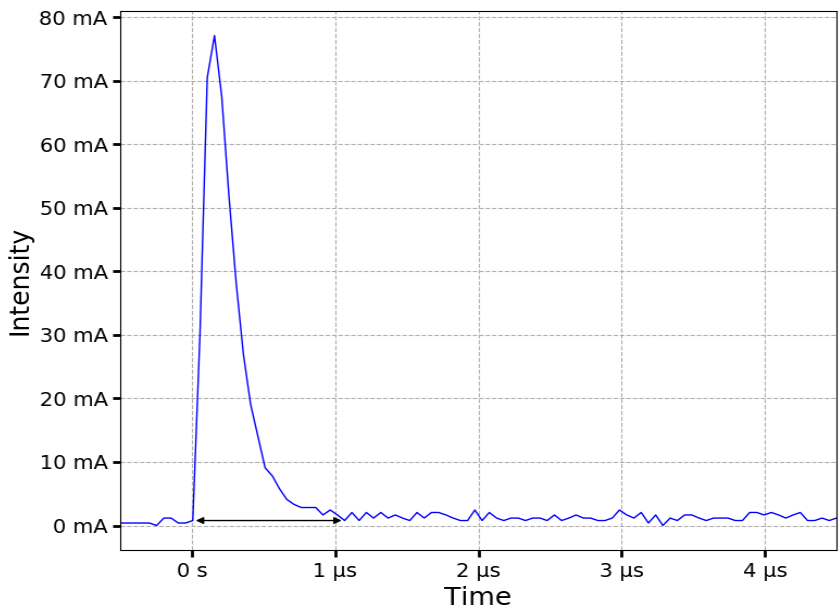

Fig. 6: A pulse of the current measurement at the lightning rod on the test pylon

The current probe at the base of the pylon has also been triggered and the current in Fig. 7 shows different behaviors. During the first $20 \mathrm{~ms}$, there is a complex corona activity. The density of corona events is higher than at the top of the pylon. Indeed, in one millisecond, there are more than 10 events that occur, as we can see in Fig. 9.

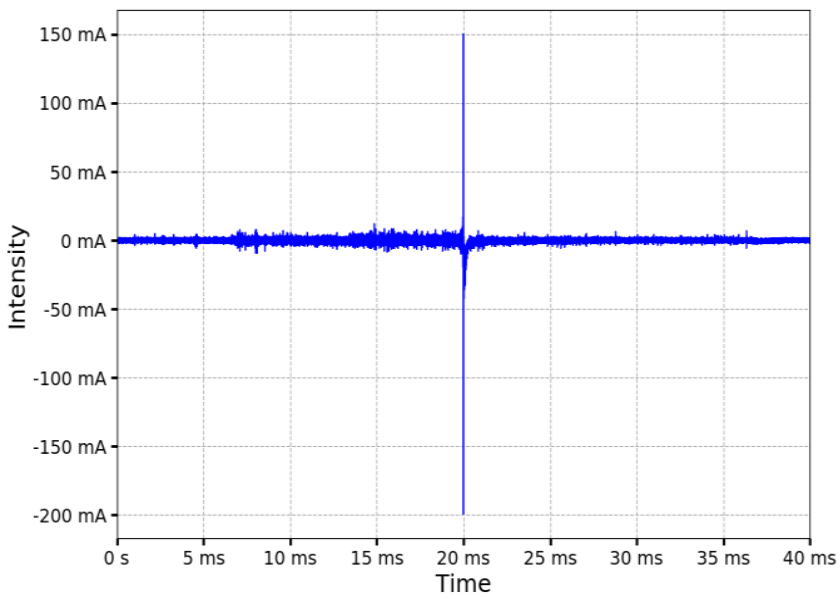

Fig. 7: Current measurement at the base of the test pylon

The second event is the pulse of very high intensity, located at $20 \mathrm{~ms}$. It is then associated with a strong electric field variation measured by the antenna, as shown in Fig. 10. This event could be identified as the next step of a corona discharge, i.e. the propagation of a leader toward the sky that stops before becoming a lightning. We can also see a resonance after the pulse on Fig. 8 that corresponds to the response of the pylon.

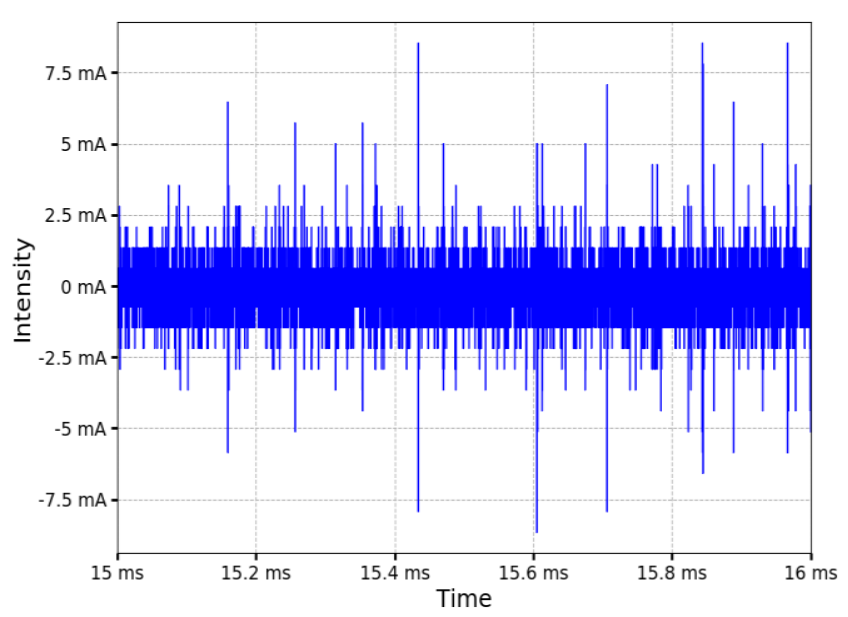

Fig. 9: Corona activity from the current measurement at the base of the pylon (between the 15th and 16th millisecond)

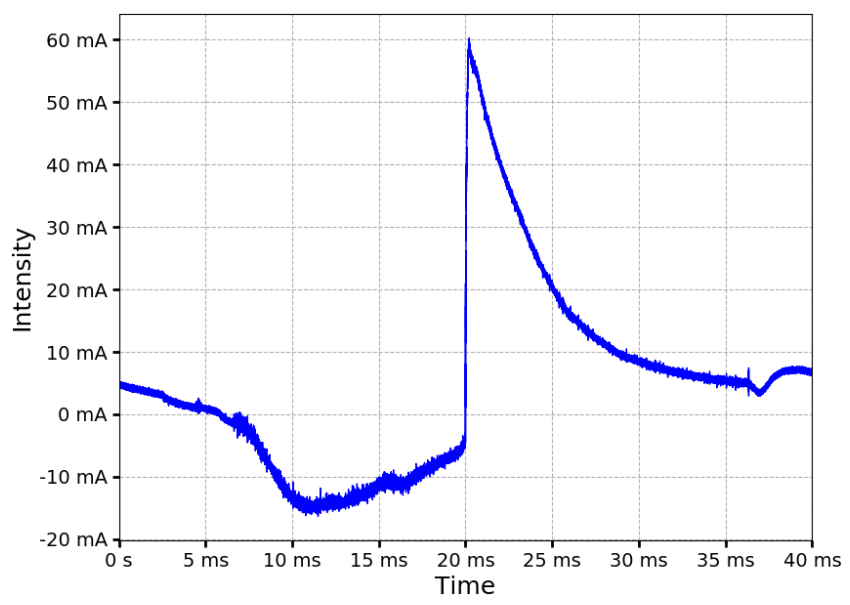

Fig. 10: Potential measurement with an antenna on the test pylon

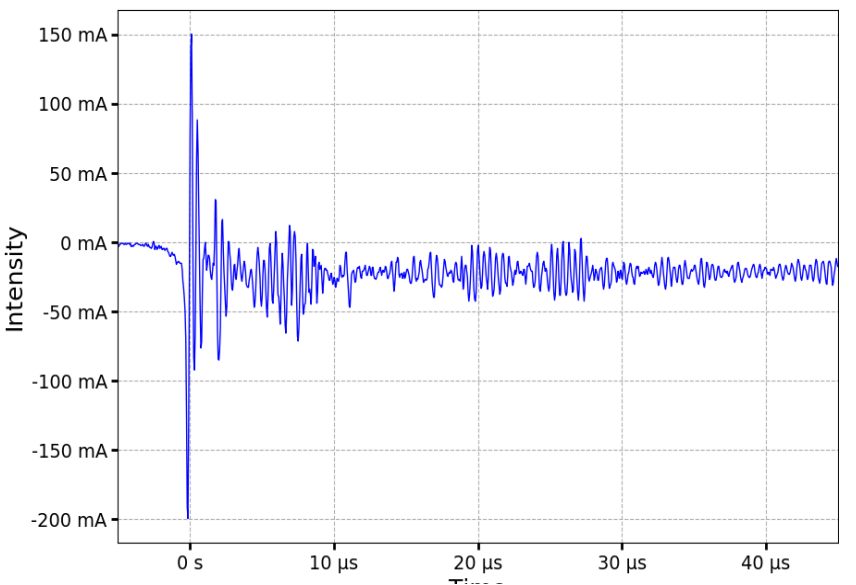

Fig. 8: Pulse and its resonance of the current measurement at the base of the test pylon

We notice that the amplitude of the pulses on the pylon can be 5 times higher than those obtained in the laboratory. It can be explained by the difference in the size of the problem, which involves a higher charge capacity and potential for the test pylon. 


\section{Conclusion}

In this article, we have presented in the first part both types of experimentation we carried out. Then, the second section shows the result obtained with these experiments. The result obtained show that there is a transfer function between the lightning conductor and the base of the pylon. Using the results obtained with these measurements will give an idea of the number of corona eventspro that occur on the pylon. Indeed, a simple measure at the base of pylon can give all the pylon currents filtered by a transfer function. Data processing will have to be carried out to find out the number of locations where corona discharges occur.

\section{Acknowledgements}

The authors would like to acknowledge, with appreciation, partial support for performed studies obtained from the Research Federation ONERA - ENAC - ISAE SUPAERO. Thanks are also due to the Technical and Innovation Department of French Civil Aviation Authority (DGAC) of Toulouse for making their test pylon available for measurements.

\section{Références}

[1] K. Arai, W. Janischewskyj et N. Miguchi, «Micro-gap discharge phenomena and television interference,» IEEE Transactions on Power Apparatus and Systems, Vols. \%1 sur \%2PAS-104, n०\%11, pp. 220-232, 1985.

[2] C. F. Clark et M. Loftness, «Some observations of foul weather EHV television interference,» IEEE Transactions on Power Apparatus and Systems, Vols. $\% 1$ sur \%2PAS-89, n%16, pp. 1157-1168, Juillet/Août 1970.

[3] H. Page et D. J. Whythe, «Corona and precipitation interference in VHF television reception,» Proceedings of the Institution of Electrical Engineers, vol. 114, n \%15, pp. 566-576, May 1967.

[4] D. J. Whythe, «Suppression of corona and precipitation-interference in VHF television reception: Thrumster experiments,» The bristish broadcasting corporation engineering division, 1963.

[5] M. WANG, «Etude des décharges corona sur les des antennes VHF soumises à un champ électrostatique naturel,» Toulouse, 2014.

[6] S. EL-Debeiky et M. Khalifa, «Calculating the corona pulse characteristics and its radio interference,» IEEE Transactions on Power Apparatus and Systems, Vols. \%1 sur \%2PAS-90, pp. 165-179, 1971. 